\title{
Investigating the Effects of Process Variables on the Residual Stresses of Weld and Laser Cladding
}

\author{
Gladys Schnier ${ }^{1, a^{*}}$, James Wood ${ }^{1, b}$ and Alexander Galloway ${ }^{1, c}$ \\ ${ }^{1}$ Department of Mechanical \& Aerospace Engineering, University of Strathclyde, Glasgow, UK \\ agladys.schnier@strath.ac.uk, bj.wood@strath.ac.uk, ${ }^{\mathrm{c}}$ alex.galloway@strath.ac.uk
}

Keywords: residual stress, weld, laser, cladding, validation, metallurgy.

\begin{abstract}
Weld cladding is investigated using a nickel alloy clad on a high strength low alloy carbon steel substrate. The effects of pre-heat temperature, clad material and post-weld heattreatment are examined, along with the potential for thinner clad layers using laser cladding. Experimental residual stress measurements show good correlation with the simulation model. Metallurgical studies illustrate good fusion between clad and substrate materials. The potential for a fatigue-resistant cladding using a stainless steel clad is discussed with the possible use of postcladding operations to enhance the outcomes for the nickel alloy clad.
\end{abstract}

\section{Introduction}

Residual stresses arising in a body post-manufacture are beneficial or detrimental to the fatigue life of a component depending on their nature. Methods such as shot-peening and autofrettage are known to induce compressive residual stresses, providing fatigue life improvement. However, welding processes and dissimilar joints, as with most machining processes, are typically known to induce tensile residual stresses, therefore shortening fatigue life. The weld cladding considered herein can be described as a dissimilar joint in essence. Where possible it would be desirable to select specific material combinations and deposition processes to induce compressive residual stresses, particularly at the surface of the component, where operational stresses are often highest.

Residual stresses are elastic and self-equilibrating in nature, arising from various mechanisms. In weld cladding, thermally generated residual stresses arise due to the non-uniform heating and cooling operations, resulting in constraint on thermal expansion and contraction in the component. The effects of three major parameters on the residual stress distribution due to weld cladding are considered. The first is the spatial and temporal variation of the clad deposition process and subsequent cooling, causing changes in microstructure due to phase transformations and chemical reactions. Secondly, the surface heat treatment effect, arising due to the variation in temperature of materials affecting the cooling rates and constraint levels within the component. And lastly, the global pre-heat shrink-fit effect, accounting for the effective shrinking of the cladding relative to the substrate, affected by material and temperature dissimilarity.

Presented herein are experimental residual stress measurements, shown to provide correlation with initial finite element simulation models for the weld cladding of two materials, nickel alloy and stainless steel, on a low alloy carbon steel substrate. The effects of weld cladding on metallurgy and material properties are discussed, introducing desirable modifications to these aspects and the residual stress distribution to increase fatigue performance. Laser cladding is also introduced as an alternative method of producing residual stresses in the same material combinations.

\section{Weld Cladding Simulation}

A recent round-robin conducted by the European network NeT [1] investigated the laying of a single weld bead, with over forty finite element simulations examining the effect of variables on the predicted residual stresses. Residual stress measurements were also conducted for validation of simulated residual stresses. The depth of such a study arising from the three-dimensional (3D) 
complex nature of the welding process was shown by the nine year timeframe over which the roundrobin was conducted. Many studies investigate accurate modelling and impact of simulation variables on predicted residual stresses, examining influences of factors such as welding heat input, manufacturing history and material constitutive models, well introduced in literature by Lindgren [2] and Goldak and Akhlaghi [3]. Initial 2D axisymmetric simulations effectively simplify the 3D cladding process to $1 \mathrm{D}$, and work is ongoing to assess the effects of accurate spatial and temporal deposition as well as the cyclic nature of the welding process variables as suggested by the work cited above. Another aspect that impacts residual stress development is that of material properties of the substrate, heat-affected zone (HAZ) and clad passes. Currently, material properties have been obtained experimentally for the entire HAZ and entire clad layer; however, due to the two passes of clad material being deposited, there will be variations in material properties through the clad layer.

Weld simulation is often achieved either by focusing on the thermo-fluid dynamics approach of modelling the physical phenomena of the molten weld pool and thermal behaviour of the HAZ or using a thermo-mechanical approach, modelling the global thermo-mechanical behaviour of the weld, focusing on the energy of the heat source [4]. Including thermal material properties from room temperature to melt temperature, along with applying the weld material at melt temperature and cooling to room temperature captures this behaviour in a simplified manner. Furthermore, in the development of the model to account for spatial and temporal variation, interpass temperatures and times are being utilized from the welding process. Rossillon and Depradeux [5] have shown that the inclusion of the last deposited pass or a reduction in the number of passes resulted in highly satisfactory residual stress distributions in comparison with multi-pass simulations of austenitic pipe girth welds. The present study indicates that a 3D multi-pass idealization is of secondary importance in this case.

\section{Material Properties}

Thermal residual stresses arise through the weld cladding process hence thermal and mechanical material properties are of particular importance. The clad material is applied at melt temperature onto a pre-heated substrate, with the whole component then cooled to room temperature in the simulation. Therefore material properties are required from room temperature to melt, capturing also phase changes which can have a significant effect on residual stress distributions. Thermal and mechanical properties are inserted into the FE model, experimentally obtained for the

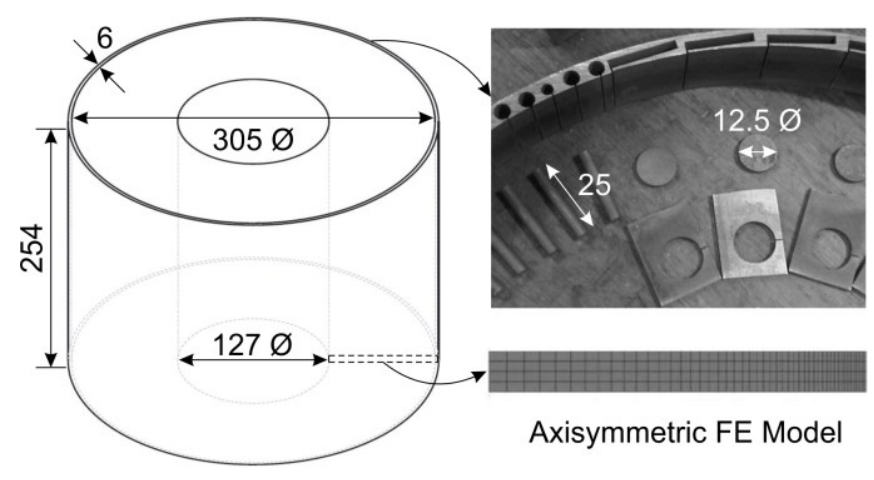

Figure 1: Sample geometry and dimensions [mm], machining of test specimens and axisymmetric finite element model. representative clad and HAZ materials using specimens harvested from the clad component as shown in Fig. 1. Table 1 shows material properties at room temperature, as applied in the simulation.

Table 1: Thermal and mechanical properties of substrate and clad materials at room temperature.

\begin{tabular}{|c|c|c|c|c|c|}
\hline & $\begin{array}{c}\text { Yield } \\
\text { Strength } \\
{[\mathrm{MPa}]}\end{array}$ & $\begin{array}{c}\text { Young's } \\
\text { Modulus } \\
{[\mathrm{GPa}]}\end{array}$ & $\begin{array}{c}\text { CTE } \\
{\left[1 /{ }^{\circ} \mathrm{C}\right]}\end{array}$ & $\begin{array}{c}\text { Specific Heat } \\
{[\mathrm{J} / \mathrm{kgK}]}\end{array}$ & $\begin{array}{c}\text { Thermal } \\
\text { Conductivity } \\
{[\mathrm{W} / \mathrm{mK}]}\end{array}$ \\
\hline CS (Ni Clad) & 869 & 206 & $9.54 \mathrm{E}-06$ & 600 & 48 \\
\hline CS (SS Clad) & 856 & 206 & $7.30 \mathrm{E}-06$ & 570 & 54 \\
\hline Ni Alloy Clad & 474 & 205 & $1.02 \mathrm{E}-05$ & 580 & 27 \\
\hline SS Clad & 994 & 197 & $6.00 \mathrm{E}-06$ & 722 & 22 \\
\hline
\end{tabular}


The literature indicates that appropriate hardening models are required for accurate residual stress prediction, with previous studies concluding that a mixed isotropic-kinematic hardening model provides the most accurate post-weld residual stress field [6]. However, in the present study, results for this particular configuration indicate that an elastic-plastic idealization is reasonable.

\section{Results}

Experimental Validation. The transformation of the clad component into an axisymmetric model is shown in Fig. 1 with results for a nickel alloy clad model shown in Fig. 2. The weld cladding process is simplified such that the clad layer is deposited onto the entire outer diameter in one or two passes. This introduces the assumption of no temperature or stress field variation in the axial and hoop directions as a function of time. The component is subjected to slow cooling with radial edges of the model insulated to simulate no axial heat transfer. Results are shown for one $6 \mathrm{~mm}$ pass and two $3 \mathrm{~mm}$ passes. The two pass method requires

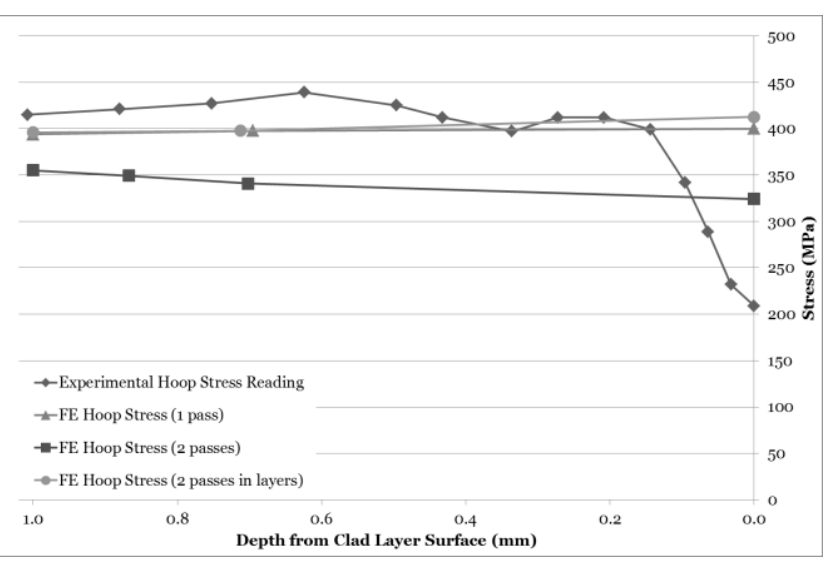

Figure 2: Validation of FE residual hoop stress in nickel alloy weld clad layer.

layering of the elements of each pass with time in consecutive steps to avoid decrease in stress levels at the clad surface. Ultimately, it would be desirable to develop the model to account for the spiralling effect of the cladding process in three dimensions, however our findings show and Wang et al. [7] confirmed axisymmetric models provide reasonable agreement with experimental residual stress distributions arising through cladding. However, Taljat et al. [8] noted that simplification of the welding process may be the cause of disagreement between tangential stress components.

Experimental validation is undertaken using the incremental center hole drilling (ICHD) method, allowing residual stress measurements to be obtained to a depth of $1 \mathrm{~mm}$ into the clad layer. This technique is a relaxation technique which allows the measurement of local displacement in the vicinity of a drilled hole using a strain gauge rosette, prior to converting strain values into stresses [9]. Residual stress measurements are obtained for cylindrical and rectangular clad specimens.

Good correlation is obtained between finite element and experimental residual stress distributions, as shown in Fig. 2. Wang et al. also reported high tensile residual stresses in a spiral nickel alloy weld overlay on low alloy carbon steel tube in the clad layer and HAZ [7].

While spot check gauges located either side of the clad/substrate boundary, on a slice taken from rectangular blocks, confirm simulation results to a greater depth, the contour method is currently under investigation due to the depth limitation of the ICHD method. This will allow the determination of detailed residual stress profiles throughout the clad layer and across the interface into the substrate.

Effects of Pre-heat Temperature and Post-Weld Heat Treatment. Fig. 3 shows the effects of pre-heat temperature and post-weld heat-treatment (PWHT) on residual stresses in a nickel alloy weld clad block. A lower pre-heat temperature results in lower tensile residual stresses, while PWHT does not decrease residual stresses. This is due to significant mismatch between clad and substrate materials. A number of measurements have been obtained on each block and cylinder, with ongoing surface preparation investigation to minimize variation in results. Investigation into decreasing stress error values suggests that optimal step increments could decrease errors to less than $20 \mathrm{MPa}[10]$. 

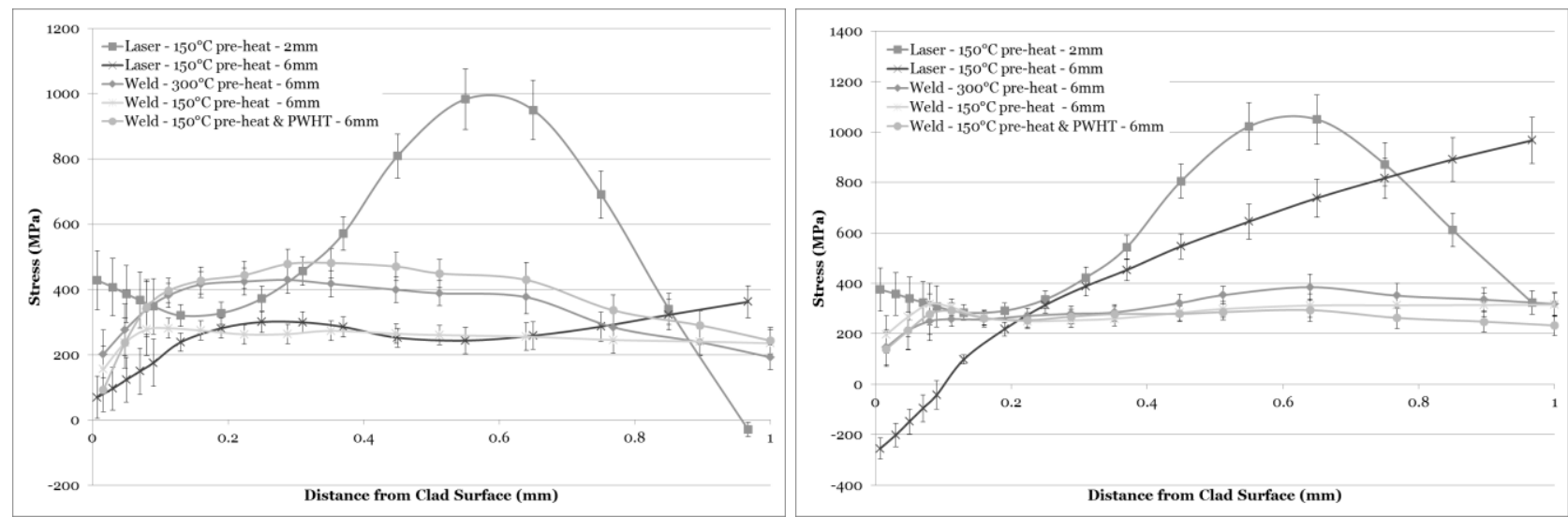

Figure 3: (a) Transverse residual stresses in nickel alloy clad on low alloy carbon steel, (b) Longitudinal residual stresses in nickel alloy clad on low alloy carbon steel.

\section{Discussion}

Modifying Residual Stress Distribution. As it is known that tensile residual stresses are detrimental to fatigue life, the residual stresses produced in the nickel alloy clad on low alloy carbon steel substrate would ideally be modified to produce compressive residual stresses in the clad layer and as deep into the substrate as possible. Fig. 4 shows the typical idealised residual stress distribution obtained for the nickel alloy clad and highlights three key areas (A, B and C) that would benefit from modification. The first goal of inducing compressive residual stresses through the clad layer, with as high a magnitude

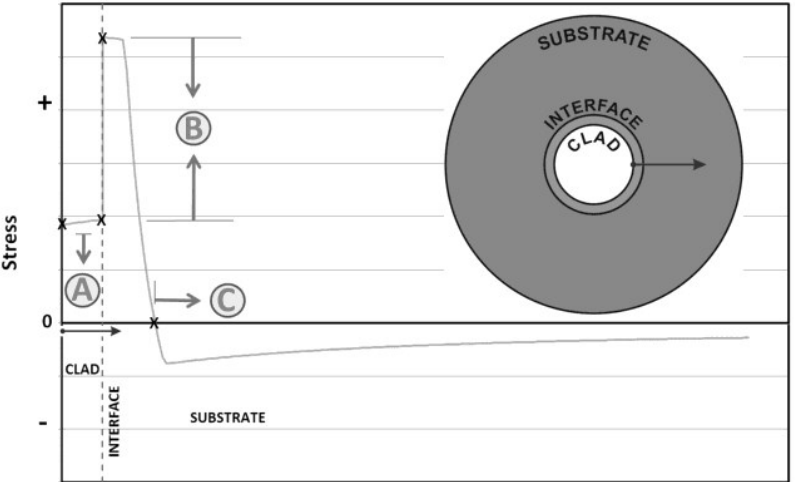

Figure 4: Goals of modifying residual stress distribution. as possible, could possibly be obtained through applying processes known to induce compressive residual stresses after the cladding process. The goal here would be achieving these beneficial compressive residual stresses throughout the entire depth of the clad layer, which would not be achieved with shot peening for example. However, autofrettage, currently under investigation, has the potential to impact residual stress distribution throughout the component. Secondly, the high discontinuity stress at the interface, if reduced, would benefit fatigue life and reduce the likelihood of cracks developing at this interface. The possibility of functionally grading the clad and substrate materials to avoid the abrupt change in materials is also being investigated through the use of laser cladding and simulation. Lastly, the transition point at which the residual stress changes sign would preferably be at as great a depth as possible, thus providing protection from fatigue failure to greater depth on the application of operational stresses in an erosive-corrosive environment. Again this could be influenced by a similar process to that used to transform tensile residual stresses in the clad layer to compressive residual stresses.

Alternative Cladding Process. Laser cladding shows promising results for decreased clad layer thickness, with similar levels of residual stresses in the nickel alloy clad to those shown in Fig. 3. However, variability in results and lack of equi-biaxiality demonstrates the need for refinement of measurement and user technique, key sources of error in ICHD. A thinner clad layer would obviously offset the increase in cost of this process to some extent. Previous studies have also demonstrated the possibility to adjust dilution through controlling the cladding speed, laser powder and feed rate [11], indicating another possible advantage of the laser cladding process. 
Metallurgical Effects of Cladding. To investigate the effects of cladding, microstructural analysis is undertaken on the clad layer and substrate materials. Fig. 5a shows a macroscopic image through a section of the weld clad and substrate. Shown clearly are the two clad passes and HAZ's along with the parent material.

Fusion between the clad material and substrate is good, with no inclusions or defects present in the clad material. However as can be seen in Fig. 5b, non-metallic inclusions are found to be present in the substrate material. The presence of these inclusions in the substrate requires further investigation.

High levels of alloy segregation occurs in the HAZ's, as shown by the light (alloy rich) and dark (alloy lean) bands in Fig. 5b, due to the slow cooling rates during the cladding process, as well as the application of pre-heat and interpass temperatures. It is found that stress relief, through high temperature soak, minimizes this effect, encouraging increased homogeneity. Increased levels of chromium and nickel, found through chemical analyses in the alloy rich areas, diffused from the clad material into the substrate, increase hardness levels in these bands as shown in Fig. 5c. In a tensile stress field, these high hardness regions could prove problematic due to resulting decreased toughness. NACE standards, relating to oil and gas applications [12], state that welding processes should be controlled such that hardness values in the weldment, HAZ and base metal do not exceed $22 \mathrm{HRC}$, approximately $250 \mathrm{HV}$.
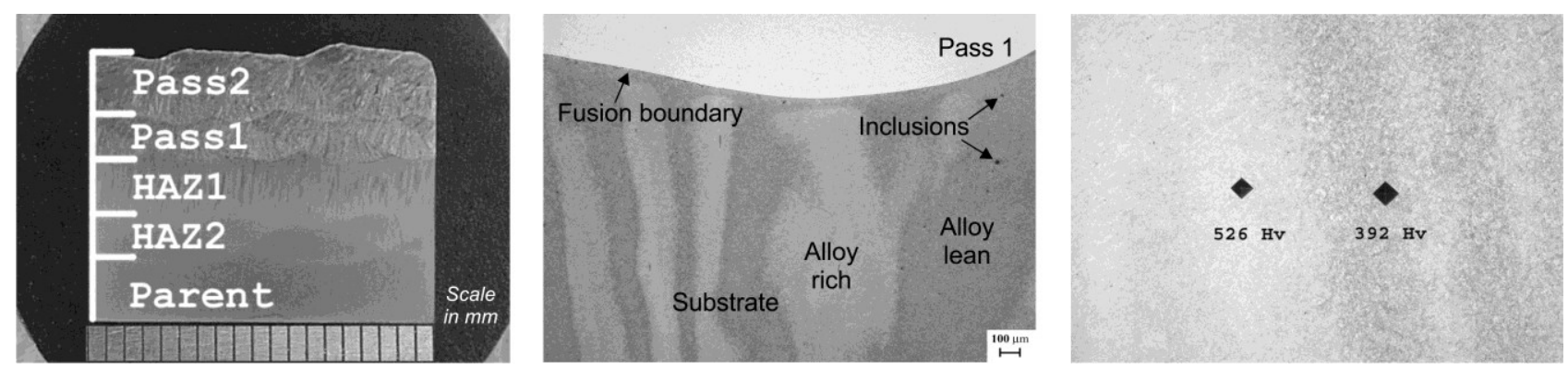

Figure 5: (a) Macrosection of weld clad and substrate, (b) Fusion boundary of nickel alloy weld clad on low alloy carbon steel, (c) Typical hardness variation in weld clad HAZ.

Investigation of laser clad specimens shows a much smaller HAZ as expected due to the smaller heat input, approximately $1 \mathrm{~mm}$ in comparison with a $6 \mathrm{~mm}$ HAZ in the case of weld cladding. Alloy segregation is again present in the substrate material with satisfactory fusion between weld and substrate. Interstitial defects are observed between clad layers and hence process refinement is required to eliminate micro-segregation. Smaller regions of high hardness levels are found in the laser clad specimens in alloy rich areas. Higher hardness values arise in areas of tempered martensite, whereas lower hardess values are found in areas with a bainitic structure. Laser cladding did not include controlled cooling, as with the weld cladding process, and so this provides potential for process refinement to obtain lower hardness values. Furthermore, chemical analyses also highlight iron dilution at a low enough level so as not to adversely affect corrosion resistance in the weld clad nickel alloy. Iron content at the surface of the laser clad is found to be much lower than at
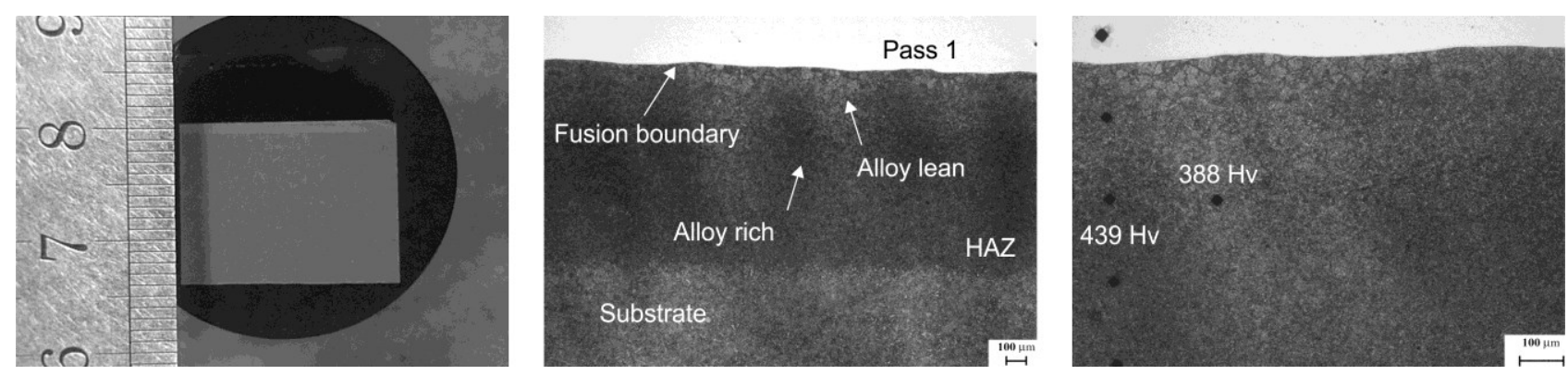

Figure 6: (a) Macrosection of laser clad and substrate, (b) Fusion boundary of nickel alloy laser clad on low alloy carbon steel, (c) Typical hardness variation in laser clad HAZ. 
the surface of the weld clad component, proving further potential benefits of the laser cladding process from a corrosion performance perspective.

Fig. 7 indicates higher hardness values in the clad layers of the laser clad blocks, which would also require further tailoring of the cladding process to decrease these values. The NACE standard provides no provision for benefit to be taken from the presence of substantial compressive residual stresses in the clad and substrate, therefore high hardness levels would require investigation and amendment of the welding process to satisfy NACE standards.

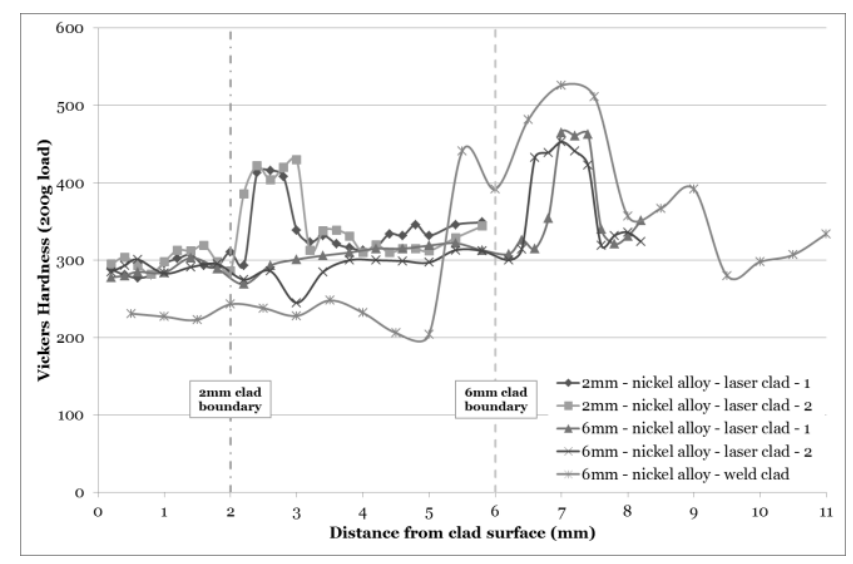

Figure 7: Comparison of hardness values in weld and laser cladding.

Alternative Clad Materials. The low alloy carbon steel substrate is also clad with stainless steel and the residual stress results for both weld and laser cladding are briefly discussed to illustrate the effects of this clad material selection. Residual stress measurements show that substantial compressive residual stresses exist in the clad layer for both cladding processes, shown in Fig. 8. These measurements illustrate the potential of material selection in producing a fatigue-resistant clad. The simulation studies show the importance of the phase change during cooling on the generation of the compressive residual stresses. It is also found that in a stainless steel weld clad, PWHT did in fact decrease the level of compressive residual stresses, shown in both stress components in Fig. 8. In this case there is a closer match between the clad and substrate in that they are both martensitic. A stainless steel laser clad on a low alloy carbon steel substrate also produces useful compressive residual stresses, in both a $6 \mathrm{~mm}$ and a $2 \mathrm{~mm}$ clad layer.
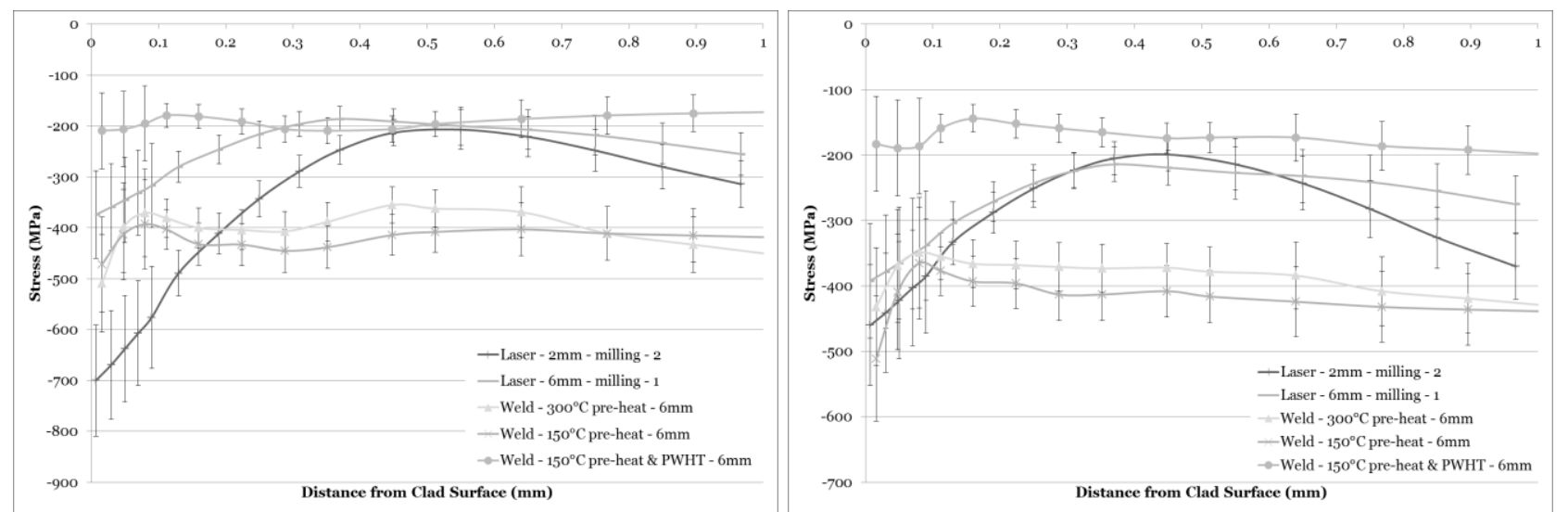

Figure 8: (a) Transverse residual stresses in stainless steel clad on low alloy carbon steel, (b) Longitudinal residual stresses in stainless steel clad on low alloy carbon steel.

\section{Conclusions}

A cladding technology producing compressive residual stresses is under investigation to exploit the beneficial effects of residual stresses on fatigue life. Simulation models show tensile residual stress arising in the clad layer and into the substrate of a nickel alloy clad on low alloy carbon steel, validated using the ICHD method of residual stress measurement.

Possible modification of the residual stress distribution arising in the nickel alloy clad component is discussed. The use of a stainless steel clad material demonstrates that compressive residual stresses can be obtained in the clad layer and into the substrate. The potential of laser cladding is also highlighted, allowing thinner clad layers and HAZ's. 
Metallurgical studies show good fusion of the clad material and substrate, with no defects or inclusions in the weld material due to the weld cladding process. Laser cladding produces certain regions of micro-segregation, requiring process refinement to eliminate these undesirable features. Alloy segregation arises in the HAZ's, producing high hardness regions in alloy rich areas. Increased homogeneity in the weld clad HAZ is achieved through PWHT.

\section{References}

[1] M. C. Smith, A. C. Smith, R. Wimpory, Review of the NeT Task Group 1 Single Weld Bead on Plate Benchmark Round Robin, 2011.

[2] L. Lindgren, Computational Welding Mechanics. Cambridge: Woodhead Publishing Limited, 2007.

[3] J. A. Goldak, M. Akhlaghi, Computational Welding Mechanics. Springer, 2005.

[4] A. Yaghi, A. A. Becker, State of the Art Review - Weld Simulation Using Finite Element Methods, University of Nottingham, 2005.

[5] F. Rossillon, L. Depradeux, A Time Saving Method to Compute Multi-Pass Weld Residual Stresses, SMiRT-22, 2013, 413-423.

[6] O. Muránsky, C. J. Hamelin, M. C. Smith, P. J. Bendeich, L. Edwards, The Role of Plasticity Theory on the Predicted Residual Stress Field of Weld Structures, Mater. Sci. Forum, 772, 2013, 65-71.

[7] X.-L. Wang, E. A. Payzant, B. Taljat, C. R. Hubbard, J. R. Keiser, M. J. Jirinec, Experimental Determination of the Residual Stresses in a Spiral Weld Overlay Tube, Mater. Sci. Eng. A, 232, 1997, 31-38.

[8] B. Taljat, T. Zacharia, X.-L. Wang, J. R. Keiser, R. W. Swindeman, Z. Feng, M. J. Jirinec, Numerical Analysis of Residual Stress Distribution in Tubes with Spiral Weld Cladding, Weld. Res. Suppl., August, 1998, 328-335.

[9] ASTM International, Standard Test Method for Determining Residual Stresses by the HoleDrilling Strain-Gage Method, West Conshohocken, Pennsylvania, E837-08e1, 2008.

[10] B. Zuccarello, Optimal calculation steps for the evaluation of residual stress by the incremental hole-drilling method, Exp. Mech., 1999, 117-124.

[11] H. Yu, T. He, C. Chen, Advancement in Ferrite-Based Alloy Coatings by Laser Cladding, Key Eng. Mater., 591, 2013, 253-257.

[12] NACE International, Metals for Sulfide Stress Cracking and Stress Corrosion Cracking Resistance in Sour Oilfield Environments, Houston, Texas, 2003. 